\title{
Contributions to the empirical study of immediacy in the pedagogical relationship through self-narratives
}

Joana Manarte, Amélia Lopes, Fátima Pereira

Abstract: Pedagogical communication is an action wherein the body, being a part of a relational whole, performs a fundamental role. A bibliographical survey of studies on the interaction between teacher and student confirms that there is a strong correlation between the teacher's nonverbal behavior and the students' level of motivation and proficiency. Nonverbal communication constitutes an indispensable vehicle for the teacher's affections, intentions and attitudes towards her students, and vice-versa. Nonverbal elements are potential promoters of immediacy, i.e., the sensation of proximity between interacting agents, which is created by the communicative behaviors. The goal of this paper is to explore some relevant aspects for the empirical study of immediacy in a pedagogical environment. It starts off from the researcher's self-narrative based upon reports of her pedagogical experiences and proceeds with an elaboration of communicative immediacy and its impact upon the pedagogical relationship and the narrator herself.

Keywords: pedagogical relationship; nonverbal communication; body; immediacy.

\section{Introduction}

When we communicate we are not only transmitting messages, but also enriching experiences, building relationships and developing attitudes, values, emotions and personalities (Stonkuvienè, 2010). This point of view is of particular importance in the educational context, a privileged place for relationship, change and social and human development. 
This article aims to explore issues relevant for the empirical study of immediacy in the pedagogical relationship as an initial contribution to the development of a wider research on immediacy in the pedagogical relationship through narratives of students and teachers. To this end, the researcher's own narratives are presented, analyzed and discussed.

\section{Communication}

Often, the term "communication" is briefly defined as a process in which verbal and nonverbal information is exchanged. However, if we also consider the functional content of communication, this setting becomes conceptually more complex.

Interaction is a reciprocal reaction by which the behavior of a participant influences the behavior of another. In the context of teaching, the teacher's action affects the student and the opposite is also true. Furthermore, this interaction is not an abstraction; it is an action that is realized in the encounter between teacher and student, so it is important to ensure physical and spiritual conditions favorable to pedagogy, circumstances facilitated by dialogue, by communication (verbal and nonverbal) (Postic, 2008; Stonkuvienè, 2010). The importance of the dialogue is something that Buber (2000) clarifies when he explains that only through the relation with a "you" we can reach and define our "I", highlighting the unique character of direct and mutual relationships.

Thus, communication is a multimodal phenomenon, expressed by the entire body, through two channels: verbal (digital communication) and nonverbal (analogue communication). Two-way channels that complement themselves in a face-to-face interaction. Verbal communication consists of representative codes where iconic or symbolic signs used (such as spoken or written words) produce a text independent of what it represents and of its encoder (Fiske 2005; Watzlawick et al., 1921). Digital communication allows a release of the immediate context, enabling time and space travel and facilitating a more rigorous definition of concepts, with less ambiguity; on the other hand, it is less expressive being more suitable for a reference to things outside of the subject.

\section{Nonverbal Communication}

Nonverbal communication is done by introducing codes (such as gestures and voice) that, being indexical, cannot refer to something independent of themselves and their encoder and indicate aspects of the issuer and its cur- 
rent situation. They are codes that convey information about the here and now (Fiske, 2005; Watzlawick et al., 1921). Analogue communication can be more ambiguous and subject to multiple interpretations, with less complexity and abstraction of the message, however, it can be more expressive and authentic and causes more immediate and intense reactions and makes known aspects of the person communicating.

Watzlawick et al. (1921) stated that all communication has content and connection, aspects secured by digital communication and analogue communication, respectively. Therefore, nonverbal communication has the purpose of transmitting indicial information - conveys information about the issuer and its situation, such as identity, emotions, attitudes, social position, and also has the function of managing the interaction in that nonverbal codes allow us to define the kind of relationship that we want to have with the other, controls participation shifts, among other elements of the interaction, thus passing information on the relationship (Fiske, 2005; Watzlwick et al., 1921). Levinas (2008) wrote that the word does not have the total transparency of the eye-to-eye, which puts the "gravitational center of a being outside of that being", meaning that being with the other is being for the other, in connection.

In the current socio-political sphere, school is often seen from an outcome point of view and not so much from the experience and relational processes. When school is seen as a cultural, spiritual and organizational entity the issue of the holistic training of the individual and the need to reflect on communication is highlighted, in this context referred to as pedagogical communication. Understanding about pedagogic interaction is still scarce and the focus on teacher has been mainly based on the knowledge of a particular theme, with insufficient attention paid to the issue of pedagogical communication (Stonkuvienè, 2010). In 1995, Jovaisa (in Stonkuvienè, 2010) published a study that reinforces the view that there are pedagogical measures that can help to solve many social and human problems, highlighting the optimization of communication in education as a key factor for the development of many dimensions of the human being.

\section{Emotion}

Despite the evidence that emotion is, culturally and cognitively, a driving force of human action, research in education has delegated emotion to a second plan favoring an overvaluation of reason or rationality in formal learning situations (Titsworth, 2010). Therefore, the quality of interpersonal 
relationships is important for the development of the emotional reaction we have not only to people but also in terms of the associated context. Applying this idea to the pedagogical environment, it is clear that students create positive/negative emotional reactions towards learning depending on the behavior of the teacher and their peers, among others. The perception the student has of the teacher is constructed by an (intuitive) analysis of their communicative acts; by the dominance of certain behaviors, student will experience satisfaction/dissatisfaction associated with that speaker. Mottet et al (2006, in Titsworth, 2010) recently presented the Theory of Emotional Response, arguing that the implicit messages conveyed by teachers (where nonverbal communication has a significant weight) provoke emotional responses in students that drive to the acceptance or rejection of learning. Teachers who have a more effective communication with their students can create a more pleasant or friendly environment, with emotional support, causing students to be more authentic in externalizing emotions, thus reducing the emotional charge (here in a negative sense) of the individuals, the group and the work environment (Postic, 2008; Titsworth et al, 2010).

\section{Communicative immediacy}

To be understood that communication, emotion and learning are highly interconnected phenomena (Titsworth et al, 2010). It makes sense to invoke the concept of immediacy, often developed by Mehrabian and that has found various definitions over time, although all of them settling on the perception of physical, emotional or psychological proximity created by positive communicative behaviors - in the pedagogical relationship, it refers specifically to the communication between teachers and students (Richmond, 2002.; Sibii, 2010). Several studies have associated immediacy in the educational context with affective learning, motivation and cognitive learning (Goodboy et al, 2009). To establish a positive, effective and affective relationship between teacher and student, nonverbal communication is equally or more important than verbal communication. Different authors clarify this idea explaining that the main function of the verbal behavior of the teacher is to provide content for the development of cognitive learning of students; whereas the core function of the teacher's nonverbal behavior is to develop in students (and with students) pleasure and interest in the subject under study, in the teacher and in the class as well as increasing motivation for continued learning. They add an aspect not to be forgotten: the construction of an affective (positive) relationship between teacher and student, achieved through effective communication reflecting positive attitudes and closeness / intimacy (Richmond, 2002; Goodboy et al, 2009; Sibii , 2010; Postic, 2008). 
Teacher's approach in the educational relationship continues to be directed by operative objectives and less available to understand socio-affective issues that may be obstructing progress. Affective learning involves feelings, emotions and students acceptance of the teacher and a specific topic. Several studies have consistently concluded that there is a strong relationship between teacher immediacy and affective learning. It should be noted that learning in an emotional scheme is so important that by contributing to the motivation of the student is also a catalyst of cognitive learning (Postic, 2008; Allen et al, 2006; Goodboy, 2009).

Nonverbal behavior of the teacher communicates meanings to students and vice versa (Richmond, 2002). In fact, nonverbal communication favors the establishment of social relations and expresses the emotions and attitudes of stakeholders. Fiske (2005, p.96) explicitly states that "The human body is the main transmitter of presentational codes". Considering the pedagogical context, we may ponder that students' perceptions of teacher's communicative behaviors, mediated through the body, tells us how effective communication is (Richmond, 2002).

The teacher who is close to their students will probably be a better teacher than one that moves away from them socially, emotionally and psychologically (Sibii, 2010). In the teacher-pupil interaction, several authors studied the immediacy of the teacher (mostly through quantitative studies) and proved its effects in the pedagogical relationship, highlighting the strong influence of nonverbal communication in interpersonal closeness or avoidance, in memorizing information and in cognitive and affective learning (Sibii, 2010; Stonkuvienè, 2010; Velez \& Cano, 2008; Hsu, 2010.; Richmond, 2002).

\section{Methodology}

Although there are already many researches in the field of communication in education, there are no studies on this topic conducted in the light of narrative methodology. And yet it would be interesting to know what students feel and think, what teachers feel and think towards other(s) in the pedagogical relationship, hoping to access a world of meaning and knowledge that points to an appealing path of personal and pedagogical experiences related to the experience of immediacy - physical, emotional and psychological created by nonverbal behaviors (and verbal) between teachers and students. At this stage the adopted methodology was the self-narrative. 
Freire (1983, p.33) states that "things do not communicate, do not tell their story. It is not this what happens with men, who are historical beings, capable of autobiography". In fact, our experiences are organized in the form of narratives, in a perpetual movement of experiences, memories and interpretations. Being inherent in human action, through narrative we represent and understand experience giving meaning to living.

Clandinin and Connelly (2011) encourage the researchers to write their own narrative as a way of launching questioning and illuminating the empirical path. I believe that what they suggest is also an exercise of identity transformation or enlightenment, leading us to reconfigure the character of the "invulnerable" researcher to the researcher who discovers, feels, mixes and humanizes him/herself when telling his/her own experience.

\section{Personal narrative}

Writing my narrative on this topic (or any other) is unweaving me in memories, perceptions and feelings. Perhaps the chronological thread might help me remember, but I do not intend that the calendar has another function here besides guiding me with memories. Moreover, what will appear are fragments made poems: I'll randomly open my memory and we'll see what comes up.

What do I remember of the teachers who made a difference for me? Why have these professors made a particular difference? How was their communicative behavior? What did their body say to me, what did they make me feel? What did they instill in me?

\section{The Primary Teacher}

The hands of the primary school teacher often smelled of orange. Hands full, dry skin, the tip of the thumb nail yellow (of peeling oranges). I know this because I remember that hand landing and gesturing in my workbook or my school manual to better explain some subject. To grasp the new information, my eyes bulged from the hand to the mouth to the eyes and to the hand again and in this nonverbal dance I now realize that I felt good at that time and nothing threatening would come from there.

I also remember the smile. I do not remember hearing her laugh, but my teacher always had a smile, albeit slight, in the face. Sometimes distant, but it was a smile. I know that when I lifted my head from what we were quietly doing and looked at her, she was looking thoughtfully at something distant and smiled. 
She touched me and my colleagues (I'm not sure if she stroked my hair from time to time when passing through my place, but I'm almost sure she did). Sometimes she pulled us through our clothing to put us in a row or draw our attention; I never liked that to be pulled from my clothes, still I do not like to see children being pulled by their clothes by kindergarten teachers. But I think my primary teacher did that with the tenderness of a mother who takes the offspring by the neck. I do not remember very specific episodes of this relationship, but I've always felt that she liked me, she liked us. And that's good.

One day she missed school and we were distributed to other classes a way of keeping us in school that day, I suppose. I went to my brother's class (I was in 2nd grade and he in 4th grade, maybe). His teacher was silently reading some girl's homework, I think it would be a "composition". At the end she hit the girl's hands with a ruler as many times as the misspellings found. I was horrified. I heard myself gasping among those still and silent (or silenced) kids and tried not to show fear that she then did the same to my brother. So I spent the rest of the class in haunted surveillance, ready to intervene as it takes to prevent it and secretly asking to some transcendent force that that would never happen to the most important boy of my life.

\section{Music}

There is a song that always takes me to my childhood days of primary school and to the prospect of a happy future. It was Christmas. There was a very large room (probably the auditorium of the parish) full of children, Santa appeared delivering presents, my teacher was grinning - the only grin I have memory in her face - as I received and opened mine. In the background "What a wonderful world" was heard loudly, sung with the magic of Louis Armstrong. The sound came from a column that was behind her, but I like to believe that the music came from heaven. A kind of holy spirit that made us golden and also created happy memories of my primary school teacher, though I don't remember specifically most of the days I spent with her.

\section{The Math Teachers}

When I went to the 7 th grade, I met a remarkable teacher. In a negative sense. I think that figure was in my head for three years. I had a conflicted relationship with the subject. Despite the curiosity and theoretical fascination for many of its issues, my reaction to everything that had to do with mathematics was loaded with bad feelings and anxiety. This pedagogical re- 
lationship produced frankly negative emotional experiences. Although I had good results in the evaluations, the emotional charge associated with that teacher and the subject was difficult for me and caused personal suffering. This interfered with personal (day-to-day) and academic decisions; I decided by what allowed me to avoid the teacher (the choice of the scientific area, for example) or made me believe that a math test would be fine. But I think I couldn't make up enough "amulet thoughts" to withdraw me from the anxiety, the fear of failure and disillusion and the willingness to give up or fail the test.

The teacher had a clear brilliance in mathematics and a perfectionist pleasure in drawing beautiful circles, triangles and graphics in the chalkboard. With controlled posture, serious facial expression, intimidating look and tuneless voice she dictated the summary at the beginning of the class like someone who dictates a law that we would write as if it were a duty. After a class question, she eagerly turned the chalk in the palm of her hand and made a question mark with her forehead as she waited for an answer. If the delay was large, she would look at me as if waiting for the right answer and I always felt bad: if answered correctly, I would feel bad because she had addressed me with a smile emphasizing the difference between those who knew the answer and those who didn't; if answered wrong, I would feel bad because of her facial and body expression of astonishment and criticism; if I didn't knew the answer, I would feel bad because I anticipated her shaking her head as she turned to the chalkboard. But above all, I felt bad for letting somebody upset me like that. The math class was tense and uncomfortable.

In the 12th grade I had another teacher. With a relaxed posture, almost always sitting in her desk, and sometimes on the chalkboard, she smiled, talking loud and shrilly (but nothing aggressive), laughing, amused. She gesticulated a lot when presenting the programme, played with facial expressions and would sat at our desk when we had a doubt and spoke of trigonometry as someone who talks about what ate for lunch. And I started to make peace with mathematics.

\section{The Portuguese Teacher}

My 11th grade Portuguese teacher looked formal; maybe classic is a more appropriate adjective. But it was as the father of Indiana Jones, an absolutely exciting classic!

He would spread in space with troubadour posture, waved his arms in the air when reading the Sermon of Saint Anthony to the Fish and in-between 
his eyes sought in ours the same enthusiasm. I remember smiling most of the classes and being dazzled by the etymology of any word that, for some reason, he decided to deploy with a passionate voice. Captivating, he would turn quickly to the chalkboard to write, talking loudly, he would turn backwards to ensure that we were following his reasoning, and would continue to speak loudly in Latin, in Greek, would turn to the chalkboard finishing explaining the transformation of the word and would turn to us with a smile and a look of surprise!

Reprimands were also made (and many) and I remember a specific episode in which he criticized someone's less emotive reading of a poem. He designed the lines of an electrocardiogram said "normal" and below a straight line corresponding to the beat of his heart when he heard us reading! For some it must have been a hard way to criticize, for others a humorous way (it was for me), but I think everyone got the message.

I believe he spoke for all without highlights. Although some colleagues didn't like that subject because they found it boring or uninteresting I believe that none would say they did not like him. I think he never realized my enthusiasm and interest, or at least never showed it. It is alright, but I would like to tell him I continue to be delighted with etymology.

\section{Other Fragments}

In higher education, a professor waved her arm and hand asking for "more, more!" answers and when she wanted to emphasize something she was saying she would beat her foot hard on the floor emphasizing every word she was saying. Her classes had a lot of energy and I loved that.

In high school, a teacher noticed that I wasn't so smiling as usual and had lunch with me. We talked and the way she looked at me said that she liked me and for her it was granted that my future would be special.

I had a teacher with the gift of the pedagogical relationship. In almost every class he made us burst out laughing. Great humor, open body posture, natural smile, gestures that gave shape to what was said, sweet voice, walking through the desks, hand on the shoulder of those whom he passed closer, sudden interruptions of the programme because some word had reminded him of a joke or a song, nodding when listening to us attentively. We all participated willingly and with content, all trying to have good results, and everyone wanted that class to arrive. 


\section{Analysis and discussion}

Talking about lived experiences implies taking into account the temporality, historicity, memory and learning, being the retrospective reflection of the experiences an active process of (co)construction of meaning (Clandinin \& Connelly, 2011; Lopes, 2011; Torregrosa, 2011; Molina, 2011). Analyzing narratives is an exercise in search for coherence and meaning in stories that are told.

Making a first analysis of these reports, it appears that the description of most of the memories of nonverbal elements of the pedagogical relationship is inseparable from the adjectives of these same behaviors. Thus, being the act of describing a subjective classification, it seems to be emerging here the relationship between nonverbal perception and the feeling associated with it.

Another curious aspect is the expressions of uncertainty that appear in the discourse, as in "I'm not sure if she stroked my hair (...) but I'm almost sure she did" or "I believe he spoke for all without highlights". Memories are vague and there is a difficulty in accessing factually past episodes and what seems to be slightly raising the veil of the story is the feeling triggered at the time, suggesting that the affective and emotional memory remained, being this perhaps one of the pillars for the act of narrating.

To facilitate reflection and enrich the discussion, some categories of analysis were thought that can be redefined according to the point of view and advance of the research (see Table 1).

Table 1

Categories of analysis

\begin{tabular}{|l|l|}
\hline Nonverbal Communication & Physical Contact \\
& Proxemics \\
& Guidance \\
& Appearance \\
& Head movements \\
& Facial expression \\
& Gestures or kinesis \\
& Posture \\
& Eye movement and eye contact \\
& Voice and verbal articulation \\
\hline Perceptions, emotions, feelings \\
\hline Relationship \\
\hline Communicative immediacy \\
\hline Impact of communicative immediacy \\
\hline
\end{tabular}


The study of the frequency of references to different nonverbal elements can bring important findings, although it seems to be a most useful type of analysis when performed with reports of multiple participants or on more extensive reports.

Considering the type and size of the self-narrative text to be analyzed here, it's interesting to see the impact of these nonverbal experiences on the narrator (researcher) and have the above categories as a list of important topics to identify and relate to.

I believe it is evidence for any reader the general classification of the pedagogical relationships portrayed here as positive or negative. Hence, we note a positive pedagogical relationship with the primary teacher, the mathematics teacher in the 12th year, the portuguese teacher and teachers mentioned under the item "Other fragments" and a negative relationship with her brother's primary teacher and the math teacher. What aspects associated with these two types of relationship arise?

The initial description on the hands of the primary school teacher brings us to the question of gestures and proxemics: the excerpt "I remember that hand landing and gesturing in my workbook or my school manual" suggests that the interpersonal distance is short and that this degree of proximity was regular, resulting in a feeling of well-being, monitoring, safety and comfort. The gestures that accompanied the explanation also evoke the idea of clarity or of something facilitator of learning. When there is reference to the facial expression, it is said that both look and smile were somewhat distant, but still there is the suggestion of a pleasant expression that did not created discomfort or awkwardness. With regard to the physical contact two types of touch are mentioned: one of affection ("she stroked my hair from time to time") and other of control/regulation ("Sometimes, she pulled us through our clothing to put us in a row or draw our attention"). Despite the dislike for the abrupt "pulling of clothes", it is as if the current interpretation excuses this past behavior, reading it now in a motherly way as a "mother who takes the offspring by the neck" or even in an innocent way. This episode regarding physical contact raises another question: that it is as important what people do to me as what I see people doing to others. Besides the idea that the teacher touched my hair, there is also the memory that she demonstrated affection for other children as well. And observing these manifestations made a whole framework of positive feelings towards that space and that person: there was a feeling of being loved and an atmosphere of affection and support. 
The episode in her brother's class highlights the importance of the teacher's behavior on the perception and emotional response of students to the point of a single contact being enough to create a negative image of the teacher and also to conceive that space as threatening and perhaps to relativize the idea of school which until then had been regarded as a safe or pleasant. Here, physical contact between teacher and student is aggressive ("hit the girl's hands with a ruler"). Again, what we see in others has also an impact on us - watching the physical assault and the "silent (or silenced) kids" unleashed feelings of fear and defense ("I tried not to show fear") reactions against the teacher ("ready to intervene as it takes to prevent it"), the feeling that her brother was in danger and the urgent need for an escape, a support or a solution made "secretly asking to some transcendent force" to help her.

The portrait of the Primary School required, in the experience of the narrator, to end in a positive manner as if to make it clear that, in general, the experience of primary school was good. In the book The Salesman of Pasts (2004) of José Eduardo Agualusa there is a character who says you only are truly happy forever in childhood. To associate music to these relational experiences seems to help, to endure or at least allows to revisit the feeling of being happy forever.

The relationship with the math teacher has a high negative emotional charge. The expression "that figure" seems to refer immediately to an intentional distancing contrasting with the words "my primary teacher" where " $m y$ " is used in a sense of closeness. The nonverbal behavior described is of stiffness, lack of involvement, distance and does not reflect any kind of emotional, physical or psychological immediacy. Rather, posture, facial expression, gaze and eye contact, guidance, nods and voice produces an emotional reaction of distance and relational avoidance.

Notwithstanding the recognition an in-depth knowledge, there is a notorious lack of communicative competence in the report. There seems to be the perception of an almost pathological perfectionism and narcissism, detached from a relational reality. Anxiety is a feeling highlighted in this interaction, in which the teacher herself reveals an anxious behavior and little tolerance: after questioning the group, "she eagerly turned the chalk in the palm of her hand", creating in students a sense of an urgent response. Although there is reference to a smile, it comes across as inappropriate and unframed of the dominant nonverbal behavior, ending up by creating a feeling of discomfort to the colleagues and, in general, nonverbal communication translated dis- 
appointment or devaluation. The influence of this pedagogical relationship is evident in the student's everyday life and feelings towards the subject in which the emotional and relational aspects eventually weighted more than her interest in the theoretical contents. To achieve satisfactory results in the evaluations a high personal, emotional and psychological effort, close to the distortion of identity and self-concept ("I felt bad for letting somebody upset me like that "), were involved, interfering with the normal day-to-day tasks ("interfered with personal (day-to-day) and academic decisions"). Having the teacher at the epicenter, the emotional earthquake was so negative that was extended to everything related to mathematics and being associated with psychological distress and displeasure.

Suddenly we find a more objective, positive, fluent and free of much explanation: the behavior of the 12th grade Math teacher. Almost contrasting with the above description, it denotes a high degree of immediacy in this relationship and indicates a feeling of relief and of healthy coexistence with the subject, shown in the phrase "And I started to make peace with mathematics" (evoking, once again, the impact that communicative immediacy has in the relationship with the teacher and with the various dimensions associated with it). Regarding the teacher's nonverbal behavior it is described has opened, available, tolerant and at ease. The voice element justifies a note: it is said that the teacher "talked loud and shrilly", vocal quality usually associated with negative aspects. Emerging in a range of positive parameters and communicative immediacy, it reminds us that nonverbal elements are so intricate that even though we can analyze them separately it is important not to forget a contextualized analysis, for what we decode in a face-to-face interaction is a set: what speaks to us is a whole body. With this teacher, notoriously, vocal quality here would be a positive feature consistent with the relational and dynamic whole described.

With the portuguese teacher it is made the first reference to appearance. It is said that the teacher "(...) looked formal; maybe classic is a more appropriate adjective". And soon after there is a need to demystify the idea of rigidity associated with the classic look, using the analogy with a comic adventurous movie figure ("as the father of Indiana Jones") clarifying that that formality crumbled into enthusiasm by highlighting nonverbal behavior. To be noted the regular visual contact in seeking the return or confirmation of the students' attention and the dynamism that accompanied the exhibition of the contents of the subject. The vocal and open and enthusiastic facial expressions captivate and contribute to pleasurable moments in the classroom. It is interesting to acknowledge that not everyone felt the same 
well-being in the classroom or at ease with the subject, although the fact that they all respected the teacher highlights the importance of the nonverbal behavior of the teacher to establish a healthy pedagogical relationship. Perhaps the enthusiasm with which he taught could be enough to captivate some students, though others might feel the need for a more close contact. In fact, touch and proxemics, for example, are not focused in this episode. The description suggests that it is a teacher so passionate about his area of expertise that he seems to live in a more "intellectual" world and somehow neglects a little the importance of being in a closer pedagogical relationship. Perhaps this explains the narrator's feeling of her interest for the subject not being recognized by the teacher. Still, there were many positive aspects to his way of being in the classroom, resulting in a continued interest in the field and a will of a reunion with the teacher ("I would like to tell him I continue to be delighted with etymology").

The episode about the teacher in higher education clearly shows the relationship between nonverbal communication and verbal communication, where the pounding of feet accompanied and accentuated oral speech and the gestures with her arm and hand enthusiastically reinforced students' participation. She transmitted energy and kept students active, converting the classroom into a good moment to experience. The expression "and I loved that" expresses a highly positive perception of this class.

Lunch with the secondary teacher draws attention to the relationship between "a luminous facial expression" and a feeling of affection and personal development. Positive experience that, among others, has probably been reflected in happy development on several levels.

In the last "piece", the first aspect mentioned to justify the "with the gift of the pedagogical relationship" is humor. Not being an exclusive aspect of nonverbal communication it is related to a way of being. Laugh, enabling laugh and making laugh deserves a highlight due to the influence it may have on the communicative immediacy and in creating an environment favorable to building a healthy and positive pedagogical relationship that influences on the student's willingness to learn. Again, body posture and smile are mentioned as indicators of openness, availability and an encouragement to participation without judgments of value. In this situation, we find elements of a close emotional and empathetic relationship with students, an attitude of active listening ("nodding when listening to us attentively") of physical and psychological proximity, having been able to create in students a desire of repeated contact ("everyone wanted that class to arrive"). 


\section{Conclusion}

The construction and analysis of this self-narrative reinforces the interplay between the nonverbal communication and emotions. Damásio (2012, p.58) writes that "the background emotions diagnosis depends on subtle manifestations such as the profile of the movements of the limbs or the entire body - the strength of these movements, their precision, frequency and amplitude - as well as facial expressions. With regard to language, what counts most for background emotions aren't words themselves or their meaning, but the music of the voice, the cadences of speech, prosody". Levinas (2008) reinforces this idea of the "transparency" and "frankness" that exist in the back of every word, stating that face to face interaction is not a "mirror game", but a phenomenon where we give our self to the other. These background emotions refer to the energy and enthusiasm that each one of us has and transmits in different degrees. The reading of these background emotions is made in the body of the other and Damásio (2012) says that anyone who can "diagnose" disorder, anxiety, excitement, and so on, in someone who has not even uttered a word then is a "great background emotions reader". The attention to detail of a teacher is something that apparently goes unnoticed, but the truth is that after 20 years we can remember details, gestures, expressions, voices, movements of our teachers and what we have felt with them.

Within this theme, the difficulty of disconnecting what is perceived from what is felt confirms that the narrative is a unique way to access either perceptions or feelings in the pedagogical relationship. Really, it's not a question of observing the nonverbal behavior of a teacher in a classroom, but to know what it feels like, which is only possible through the report of experiences. In this sense, the narrative comes to embody the intangible dimension of affect and stands as an appropriate methodology for the study of immediacy in the pedagogical relationship.

Another aspect to bear in mind for the empirical study of communicative immediacy through narratives is the need to travel on the timeline in an attempt to establish connections between the past history, how it is told and the impact of those experiences in today's future. Equally important is the ecological context of the narrator, here facilitated by storyteller and researcher being the same person. In another situation, the relationship between researcher and narrator is central to a coherent interpretation of the reports and to deprive actual meaning of the experiences narrated. 


\section{References}

Allen, M., Witt, P.L., \& Wheeless, L.R. (2006). The role of teacher immediacy as a motivational fator in student learning: Using meta-analysis to test a causal model. Communication Education, 55 (1), 21-31.

Buber, M. (2000). I and thou. New York: Scribner.

Clandinin, D.J., \& Connely, F.M. (2011). Pesquisa narrativa, experiências e história na pesquisa qualitativa. Minas Gerais: EDUFU.

Damásio, A. (2012). Ao Encontro de Espinosa. As emoções sociais e a neurologia do sentir. Lisboa: Temas e Debates, Círculo de Leitores.

Fiske, J. (2005). Introdução ao estudo da comunicação (9 $9^{\text {a }}$ Ed.) Porto: ASA Editores. Freire, P. (1983). Extensão ou Comunicação? (7 ${ }^{a}$ Ed.) Rio de Janeiro: Paz e Terra.

Goodboy, A.K., Weber, K., \& Bolkan, S. (2009). The effects of nonverbal and verbal immediacy on recall and multiple student learning indicators. Journal of Classroom Interaction, 44 (1), 4-12.

Hsu, L. (2010). The impact of perceived teachers' nonverbal immediacy on student's motivation for learning English. Asian EFL Journal, 12 (4), 188-204.

Levinas, E. (2008). Totalidade e infinito. Ensaio sobre a exterioridade ( $3^{\mathrm{a}} \mathrm{Ed}$.) Lisboa: Edições 70.

Lopes, A. (2011). Las historias de vida en la formación docente: orígenes y niveles de la construcción de identidade de los professores. In F. Hernandéz, J.M. Sancho \& J.I. Rivas (Orgs.), Historias de vida en educación: biografias en contexto (pp. 23-33). Barcelona: ESBRINA.

Molina, D. (2011). Asumir la tensión entre lo social y lo humano al hacer historia de vida. In F. Hernandéz, J.M. Sancho \& J.I. Rivas (Orgs.), Historias de vida en educación: biografias en contexto (pp. 90-98). Barcelona: ESBRINA.

Postic, M. (2008). A relação pedagógica ( $2^{\mathrm{a}}$ Ed.) Lisboa: Padrões Culturais.

Richmond, V. (2002). Teacher nonverbal immediacy: use and outcomes. In J.L. Chesebro \& J.C. McCroskey (Eds.), Communication for teachers (pp. 65-82). Needham Heights, MA, USA: Allyn \& Bacon.

Sibii, R. (2010). Conceptualizing teacher immediacy through the 'companion' metaphor. Teaching in Higher Education, 15 (5), 531-542.

Stonkuvienè, I. (2010). Communication as an essential element of pedagogical process. TILTAI, 4, 189-200.

Titsworth, S., Quinlan, M., \& Mazer, J. (2010). Emotion in teaching and learning: development and validation of the classroom emotions scale. Communication Education, 59 (4), 431-452.

Torregrosa, A. (2011). Historias de vida y conectividades emergentes. In F. Hernandéz, J.M. Sancho \& J.I. Rivas (Orgs.), Historias de vida en educación: biografias en contexto (pp. 126-131). Barcelona: ESBRINA.

Velez, J.J. \& Cano, J. (2008). The relationship between teacher immediacy and student motivation. Journal of Agricultural Education, 49 (3), 76-86.

Watzlawick, P., Helmick, B., \& Jackson, D. (2007). Pragmática da comunicação humana: um estudo dos padrões, patologias e paradoxos da interação. (16 ${ }^{a}$ Ed.) São Paulo: Editora Cultrix. 


\section{Author:}

Joana Manarte, Ph.D. Student

University of Porto

Faculty of Psychology and Educational Sciences

Educational Research and Intervention Centre

Rua Alfredo Allen

4200-135

Porto

Portugal

email: joanamanarte@gmail.com

Amélia Lopes, Full Professor

University of Porto

Faculty of Psychology and Educational Sciences

Educational Research and Intervention Centre

Rua Alfredo Allen

4200-135

Porto

Portugal

email: amelia@fpce.up.pt

Fátima Pereira, Assistant Professor

University of Porto

Faculty of Psychology and Educational Sciences

Educational Research and Intervention Centre

Rua Alfredo Allen

4200-135

Porto

Portugal

email: fpereira@fpce.up.pt 